\title{
Adverse effects of night shift work on mental and physical fatigue of taxi drivers
}

Hiroshi Ikeda (Advanced Research Institute for Natural Science and Technology, Osaka City University, ikeda@ado.osaka-cu.ac.jp)

Shigeyuki Minami (Advanced Research Institute for Science and Technology, Osaka City University, minami@elec.eng.osaka-cu.ac.jp)

Kazuko Richards (Institute for ErgoSciences, ckcyp512@sutv.zaq.ne.jp)

Masaru Nakaseko (Osaka Occupational Health Support Center, mn_nakaseko@yahoo.co.jp)

\begin{abstract}
Long hours of work, including night shifts, for taxi drivers are one of the primal risk factors for health and well-being. Many studies indicate that long working hours are associated with the development and exacerbation of cerebrovascular and cardiovascular diseases, and taxi drivers work longer hours than drivers of other transport services. Taxi companies have been emphasizing measures to promote napping as a way to reduce fatigue associated with adverse effects on bodily functions. This paper aimed to examine the influence of naps on fatigue recovery through a questionnaire survey of 126 taxi drivers engaged in night work regarding: (1) the frequency of reported complaints of drowsiness and fatigue while driving, (2) the status and effects of napping in the vehicle during night work, and (3) physical fatigue related to the musculo-skeletal system from a constrained driving posture. The results revealed that it is difficult to take a nap due to the high demand to pick up passengers. The time series variation of drowsiness and fatigue during driving, and the localized physical fatigue to parts of the body related to driving were also discussed. Improvement of resting schedules, including a nap time to reduce task conflicts physically and mentally, was emphasized.
\end{abstract}

\section{Keywords}

taxi driver, long driving hours, drowsiness, fatigue, questionnaire survey

\section{Introduction}

Taxi services in cities are a convenient and important means of transportation for customers, especially travelers. Train and bus connections are unique in each country and are difficult to use without understanding the language. In that respect, a traveler only needs to tell a taxi driver a destination, and the taxi will transport the customer and a large travel bag there. For individual travelers, taxis are a very attractive and convenient means of transportation. Since the Road Transport Law in Japan (2002) was amended, the number of taxies has increased, and the increase has intensified the competition among taxi companies. This led to a prolongment of working hours, including late-nights, to supplement the incomes of their employees and enterprises [Japan Federation of Hire-Taxi Associations, 2012]. Such intensified driving work is related to high demand, low control and low support, and consequently increased risk of occupational health disorder.

Night shift work has a negative impact on health and wellbeing among workers due to the disturbance of psychophysiological functions that are antagonist to the circadian rhythm. Irregular sleep and waking cycles are more likely to cause accumulation of fatigue than day-time work [Colquhoun, 1971; Rutenfrants et al., 1976; 1977]. Regarding the physical and mental health problems of night shift workers, Grandjean [1988] pointed out that a negative impact against circadian rhythm (a body that operates in a 24-hour day and night rhythm) causes sleep debt. There is a risk of life-style-related diseases if there is not enough time to avoid disturbance of sleeping and eating habits [Covassin and Singh, 2016; Ikehara et al., 2009,
Knutson, 2010; Pejovic et al., 2013]. Dawson and Reid [1977] showed that the working capacity of people working for long hours at night was reduced to the level of people driving under the influence of alcohol.

Taxi enterprises are recommended to facilitate a sleeping environment that allows their drivers to have daytime sleep at the end of each night-shift. Shortage and low quality of sleep are linked to problems with the digestive system and sleep deprivation [Ono et al., 1995]. Hitosugi et al. [2008; 2015] describe how about $30 \%$ of taxi drivers in Japan cannot take a day off even if they show strong or frequent stomach complaints and intestinal discomfort, and they also suggest that most taxi drivers are more vulnerable to cerebrovascular and heart disorders. The Japan Federation of Hire-Taxi Association [2019] showed that the annual income of taxi drivers is about $60 \%$ of the average for all industries, while their working hours are longer than the average for all industries.

Poor management of shift schedules allows the drivers to use their free day or break time for working extra hours, which is not only a socially undesirable approach, as it leads to long working hours, but is also counteractive to work performance and to their daily health. Also for other professional drivers, Funakoshi et al. [2003] point out the similar problem of physical fatigue found among other professional drivers, resulting from having constrained posture in the driver seat and exposure to whole-body vibration for a long period of time. In this study, a questionnaire survey was carried out on drowsiness, fatigue and musculo-skeletal pains; nighttime naps in the vehicle were rated in order to collect occupational health information on taxi drivers; and suggestions are made for a contribution to the prevention of overwork driving. 


\section{Method}

\subsection{Participants}

The subjects of this survey were 126 male drivers who worked a night shift schedule for a taxi company in O City. The average age of the drivers was 59.1 with $S D=7.4(S D$ : Standard Deviation), and the average number of years of work experience was $13.4(S D=11.5)$. The characteristics of the drivers surveyed are shown in Table 1. Japanese taxis consist of a sedan type, hire type, and jumbo type. In this survey, sedan type taxis were most common.

Table 1: Characteristics of subjects

\begin{tabular}{lc}
\hline Number of subjects & 126 persons \\
\hline Sex & male \\
\hline Average age & 59.1 years $(S D: 7.4)$ \\
\hline Work experience & 13.4 years $(S D: 11.5)$ \\
\hline
\end{tabular}

\subsection{Questionnaire survey and procedure}

The questionnaire consisted of items related to: (1) the frequency of drowsiness and fatigue during driving, (2) the situation and effects of naps in the vehicle at night, and (3) physical fatigue during night shifts for taxi drivers. The questionnaire was distributed to each subject under the supervision of a taxi company in O City. The drivers received the questionnaire on the day of the survey before work and filled out the answer after finishing work on the day. After the questionnaire was completed, it was sealed by the subject themselves and returned by post. The answers to the questions are voluntarily, and it is shown in the document that it is not necessary to answer if the driver has no intention.

\section{Results}

\subsection{Effect of nighttime nap in the vehicle on drowsiness and fatigue while driving}

Figure 1 shows the rate of reported drowsiness when driving at night. The answer was required by selecting one of three categories: "frequently", "sometimes", and "nothing" for drowsiness. As shown in the figure, $69.3 \%$ of drivers complained of drowsiness while driving, and $14.9 \%$ of them answered that drowsiness was "frequent". However, there was no statistically

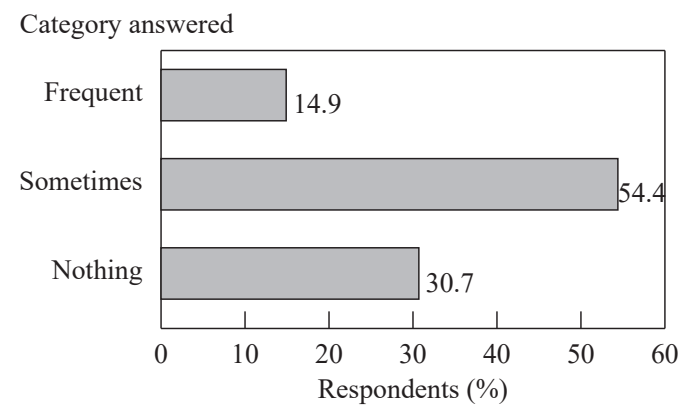

Figure 1: Distribution of drowsiness while driving significant difference between age and work experience.

Figure 2 shows the results of sleep status of a nap in the vehicle during breaks. The sleep status obtained was rated on a scale of 4 categories corresponding to $100 \%$ of sleep status over the period of breaks, which was expressed by the following categories: "3/4 can sleep", " $1 / 2$ can sleep", "1/4 can sleep", and "almost no sleep". As a result, $21.9 \%$ of drivers answered that they could sleep for more than half of the nap time. On the other hand, $51.8 \%$ of drivers answered that they could hardly sleep, and $78.2 \%$ when added to " $1 / 4$ can sleep".

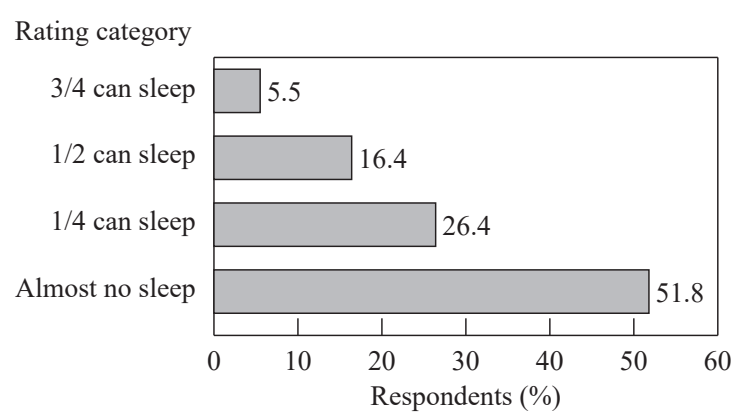

Figure 2: Sleep situation of nap Note: The break time set to $100 \%$.

Figure 3 shows the evaluation of a nap time length in the vehicle. $41 \%$ of the drivers reported that they took a nap of 1 hour or less, and $43.9 \%$ reported that they did not take a nap. As shown in Figure 1, about $70 \%$ of drivers felt drowsiness while driving. Nap time length was less than an hour even though adding the reported number which did not take a nap in the vehicle during the break time to the reported number which took a nap $\left(\chi^{2}=10.09, d f=3, p<0.05\right)$.

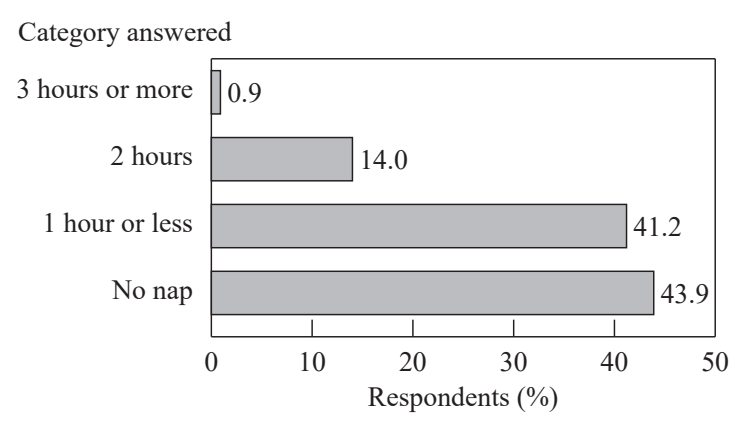

Figure 3: Length of nap time

Concerning taking a nap at night as shown in Figure 4, it was evaluated that the recovering feeling was more effective for drowsiness than for fatigue in the vehicle $\left(\chi^{2}=62.08, d f=2, p\right.$ $<0.01) .37 .5 \%$ of the respondents answered that they were not able to recover or recover a little from fatigue by a nap. Regarding the drowsiness, $30.4 \%$ of drivers answered that they could "reduce/recover well". This result suggests that a nap was more effective in drowsiness than in mental and physical fatigue.

Figure 5 shows an evaluation of the reported responses (\%) 


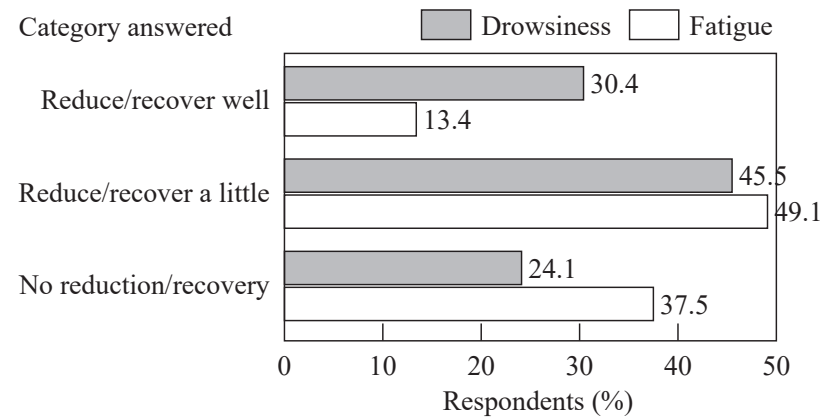

Figure 4: Evaluations of drowsiness and fatigue by a nap

of drowsiness and fatigue throughout a 24-hour time scale during driving work and activity for other work. The drowsiness of drivers working a night shift was found to increase in the period of 1:00 to 4:00, with the highest time at 3:00. Fatigue also occurred in a similar trend as drowsiness with a peak at 2:00. Also in the daytime, both fatigue and drowsiness were found to increase in the period of 13:00 to 15:00 after lunch.

\subsection{Fatigue and health impairment related to driving work}

Figure 6 shows the results of a category rating scale of fatigue. Answers to the questionnaire item consisted of three categories: "feel", "feel a little", and "do not feel". The result shows that "feel" fatigue was $41.7 \%$ of drivers, and "feel a little" fatigue was $44.3 \%$, and "not feel" fatigue was $13.9 \%$ of

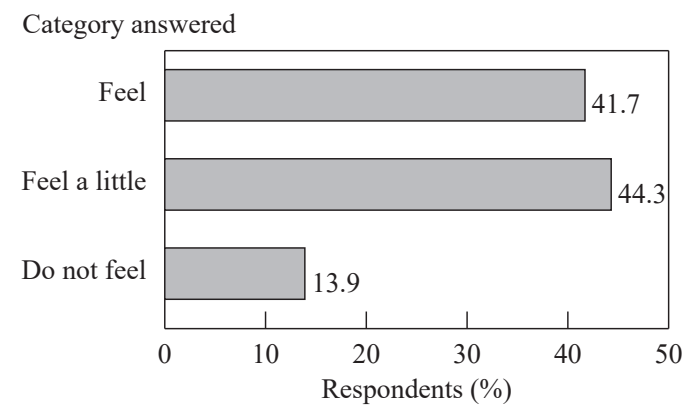

Figure 6: Carrying over fatigue during night shifts drivers.

Figure 7 shows reported complaints of stiffness, dullness, and pains in 10 localized areas of the body. The complaints of fatigue were mostly the eyes, shoulders, and lower back, which exceed $15 \%$ or more. The physical complaint was $10 \%$ or more in the neck, and $5 \%$ or more in the back, arm, knee and ankle/sole. The high complaint rate of shoulder and lower back suggested that it is related to the ergonomic factors of driving movements and postures.

Figure 8 shows a comparison of the driver's past medical experience ratio with the reported complaint rate of physical muscle fatigue (dullness, damage) in driving work. Rates of the past medical experience were $40.8 \%$ in the lower back pain, and $33.9 \%$ in the neck, shoulder and arm disorders. On the other hand, the past medical experience from the lower back while driving was $14.2 \%$ of "always" and $61.7 \%$ of "sometimes", and the combined total is $75.9 \%$. In other words, drivers who have visited a hospital for lower back pain showed a more severe degree of fatigue which it was difficult to recover from through one night of sleep (lower back pain: $\chi^{2}=28.50, d f$ $=2, p<0.01$, neck, shoulder and arm pain: $\chi^{2}=16.18, d f=2, p$ $<0.01)$.

\section{Discussion}

The results of the questionnaire survey revealed that $70 \%$ of taxi drivers showed reported complaints of drowsiness after a night shift, and a lack of opportunity to have a nap during the break time. Most of them reported that it was impossible to sleep in the vehicle resulting from high and conflicting demands, such as time pressure for taking passengers. In the time for a normal break, the drivers were required to run their tasks because of a low autonomy situation depending on their wages. This is addressed to improving the amount of the driver's wage.

The lack of a rest time, including a nap time, is not only for a taxi driver but also for other transport drivers such as bus and truck drivers. According to the standards set by the Ministry of Land, Infrastructure, Transport and Tourism in Japan, long-

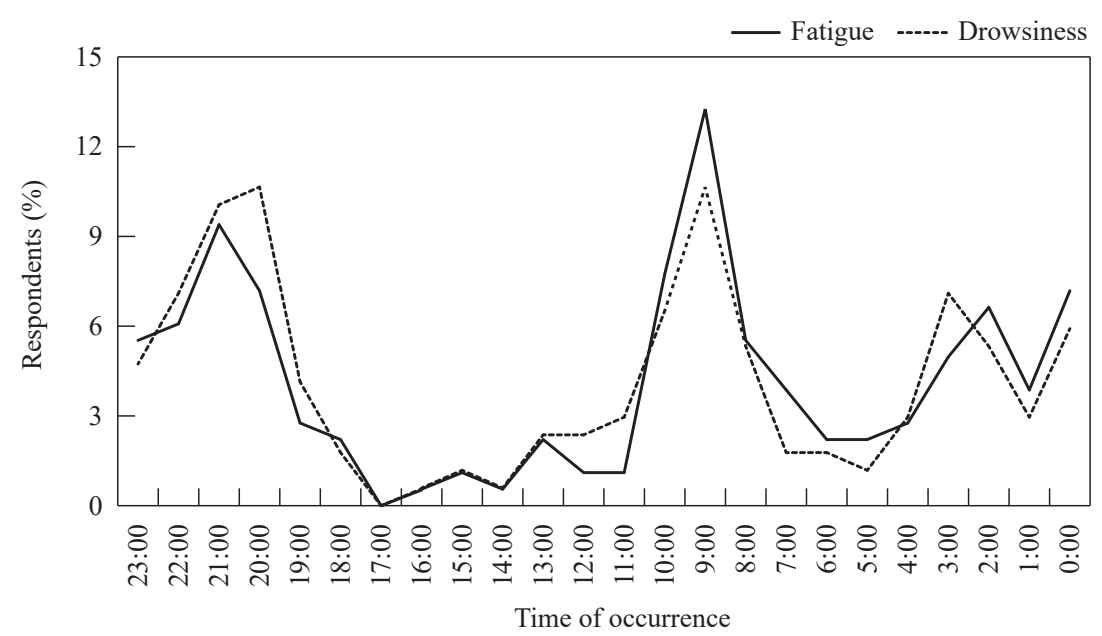

Figure 5: Time of occurrence of drowsiness and fatigue 


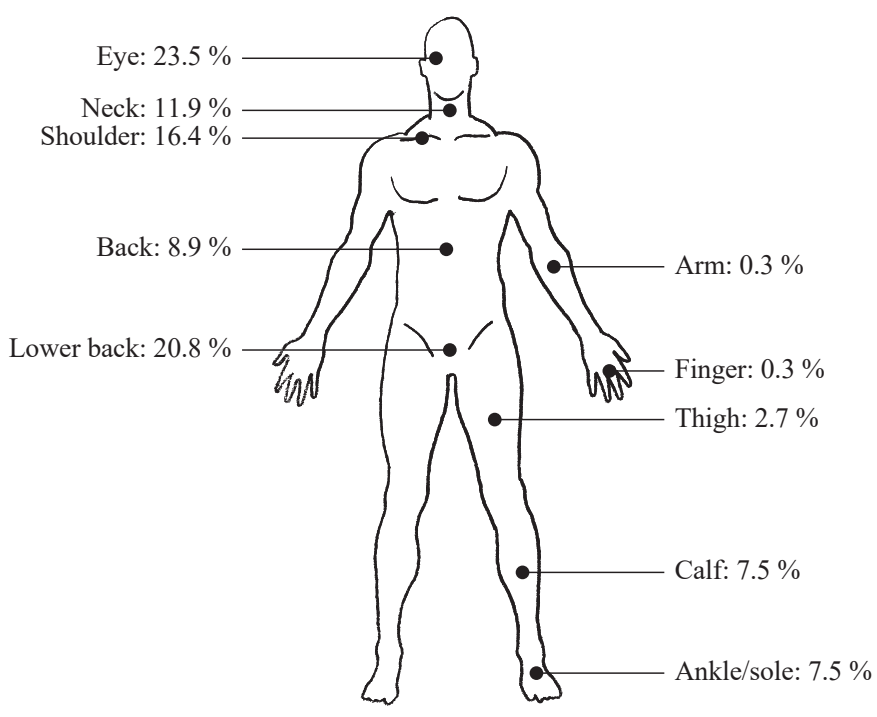

Figure 7: Distribution of localized fatigue in the body

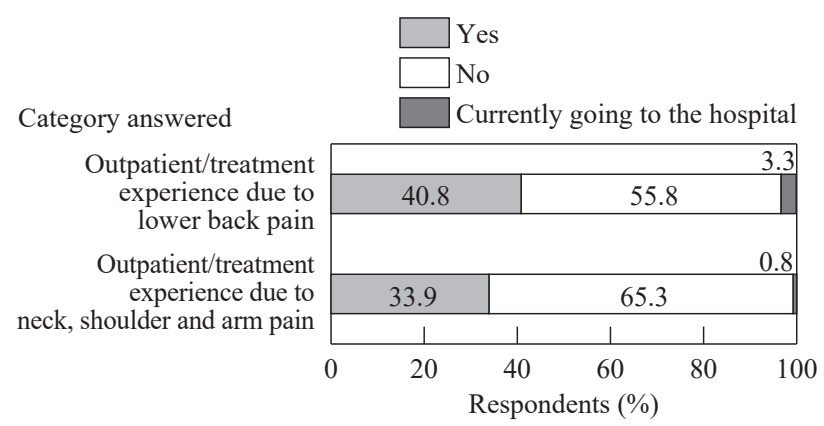

(a) Experience of going to hospital due to lower back pain and neck, shoulder and arm pain

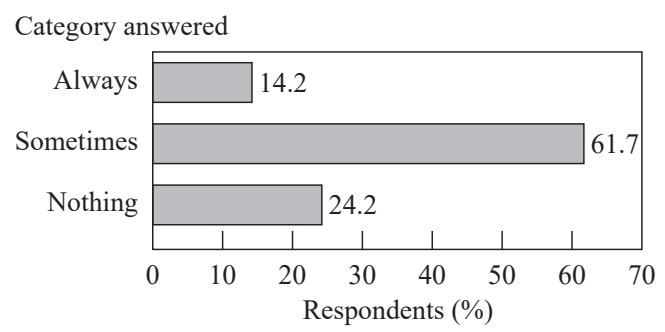

(b) Frequency of muscle fatigue in the lower back during driving

Figure 8: Muscle fatigue due to hospital visit experience and driving

distance highway bus drivers with fixed routes must take a break of at least 15 minutes every two hours. It can be said that the bus driver changes to another driver every two hours and the first driver can take a two-hour rest time in the nap cabin in the bus. The long-distance bus has a cabin (rest space) in the bus, equipped with blankets and air conditioning so that the driver can sleep even in such a simple space, and this environment makes it possible for the driver to take a nap. There is also a report that nighttime naps are of higher quality than daytime sleep, even in a bus [Ikeda et al., 2006]. In Japan, compared to Europe and the United States, there are many cases in which a system that allows nighttime naps is adopted in production industries other than bus transport services [Matsumoto et al.,
1982].

However, there is not enough space in the driver's seat for a nap during break time, and about $50 \%$ of drivers answered that they could hardly sleep, and about $40 \%$ did not take a nap. A nap is considered to be more effective in preventing drowsiness than recovery from fatigue. Continuous work leads to a low level of attention and a high level of error, and if moderate sleep deprivation continues, the cumulative effects cause intense drowsiness [Belenky et al., 2003]. Subjective feelings of drowsiness and fatigue indicated a similar trend with the high level of reported complaints at both 2:00 to 3:00 and 14:00 of the working hours. This result suggests that it is effective to take break time in order to recover from fatigue at those times. 
In addition, it was revealed that about $40 \%$ of drivers carried over localized fatigue of the body due to night shifts. It can be said that the taxi driver has a high risk of lower back pain because they stay in a sitting position for a long time and also bear the burden of vibration on the lumbar intervertebral disc due to the running of the engine. In addition, keeping the arm in a fixed position for steering is also suggested to be related to a high complaint rate of muscle fatigue.

\section{Conclusion}

Night shifts are not only accompanied by irregular sleep hours, but also reduce sleep time and quality. In daytime sleep, it is difficult to attain a good sleep similar to when the body follows a circadian rhythm. By a prolonged and repeated disturbances of sleep over work fluctuation, the drivers always feel tired and experience difficulty with concentration levels, even during work. As for the physical complaints, many drivers reported fatigue on their eyes, shoulders, and lower back area, and most of the complaints were carried over to the next day. It can be strongly suggested that the frequent and strong complaints of drivers who work at night about the accumulation of fatigue are true. It is very important to take regular breaks during the shift for working at night and also long hours. However, in the case of a private taxi driver, there are conflicting demands between earning a good wage and a decrease in the driver's wage. Even if the driver is employed, the driver's wage is also reduced if the number of passengers is reduced. Therefore, the drivers should be provided with a remuneration or a compensation for hours without break time not only in excessive hours, but also in normal hours for driving work. Especially, having free or rest time is important for taxi drivers to recover from their daily fatigue as a way to prevent accumulated fatigue. Before the onset of severe complaints from drivers about their bodies resulting from intensive work, it is necessary for taxi enterprises to compensate the drivers with enough time for them to rest and recover from fatigue, even in the vehicle. At the same time, it is necessary for taxi enterprises to improve the sleeping environment by providing drivers with a nap room and to establish guaranteed possibilities for work as well as resting schedules for their sustainable health. This study requires more information to provide a possible resting schedule for taxi drivers and taxi companies.

\section{References}

Belenky, G., Wesensten, N. J., Thorne, D. R., Thomas, M. L., Sing, H. C., Redmond, D. P., Russo, M. B., and Balkin, T. J. (2003). Patterns of performance degradation and restoration during sleep restriction and subsequent recovery: A sleep dose-response study. Journal of Sleep Research, Vol. 12, No. 1, 1-12.

Colquhoun, W. P. (ed.) (1971). Biological rhythm and human performance. London: Academic Press.

Covassin, N. and Singh, P. (2016). Sleep duration and cardiovascular disease risk: Epidemiologic and experimental evi- dence. Sleep Medicine Clinics, Vol. 11, No. 1, 81-89.

Dawson, D. and Reid, K. (1997). Fatigue, alcohol and performance impairment. Nature, Vol. 388, 235-237.

Funakoshi, M., Tamura, A., Taoda, K., Tsujimura, H., and Nishiyama, K. (2003). Risk factors for low back pain among taxi drivers in Japan. Sangyo Eiseigaku Zasshi, Vol. 45, No. 6, 235-247. (in Japanese)

Grandjean, E. (1988). Fitting the task to the man: A textbook of occupational ergonomics, 4th edition. Taylor \& Francis.

Hitosugi, M. and Ohkubo, T. (2008). Takushī unten-chū no byōki hasshō rei ni tsuite no kaiseki: Rōdō kankyō to hasshō jōkyō o kangaeru [Analysis of illness cases while driving a taxi: Thinking about the working environment and the onset situation]. Journal of the Japanese Council of Traffic Science, Vol. 8, No. 2, 27-31. (in Japanese)

Hitosugi, M., Yamauchi, S., Hasegawa, M., Takasou, M., Miyama, G., and Koseki, T. (2015). Survey for taxi drivers regarding the health-related vehicle collisions and preventive measures. Journal of the Japanese Council of Traffic Science, Vol. 15, No. 2, 50-57. (in Japanese)

Ikeda, H., Ikeda, H., Mihoshi, A., and Nakaseko (2006). Effects of nighttime nap and daytime sleep on heart rate and drowsiness in long-distance highway bus drivers. IATSS Research, Vol. 30, No. 2, 78-82.

Ikehara, S., Iso, H., Date, C., Kikuchi, S., Watanabe, Y., Wada, Y., Inaba, Y., Tamakoshi, A. (2009). Association of sleep duration mortality from cardiovascular disease and other causes for Japanese men and woman: The JACC study. Sleep, Vol. 32, No. 3, 295-301.

Japan Federation of Hire-Taxi Associations (2019). Takushī unten-sha chingin rōdō jikan no genkyō: Heisei 30-nen chingin kōzō kihon tōkei chōsa [Current status of taxi driver wages and working hours-2018: Wage structure basic statistical survey]. (in Japanese)

Japan Federation of Hire-Taxi Associations (ed.) (2012). Haiyā takushī nenkan 2012-nenban [Hire taxi yearbook 2012 edition]. TokyoKotsu Shimbun. (in Japanese)

Knutson, K. L. (2010). Sleep duration and cardiometabolic risk: A review of the epidemiologic evidence. Sleep Medicine Clinics, Vol. 24, No. 5, 731-743.

Matsumoto, K., Matsui, T., Kawamori, M., and Kogi, K. (1982). Effects of nighttime naps on sleep patterns of shiftworkers. Journal of Human Ergology, Vol. 11, Supplement, 279-289.

Ono, T., Yoshida, M., Nakazono, N., and Hara, I. (1995). Sleeping and eating cycles of taxi drivers working a 24-hour shift. The Journal of Kansai Medical University, Vol. 47, No. 1-2, 76-82. (in Japanese)

Pejovic, S., Basta, M., Vgontzas, A. N., Kritikou, I., Shaffer, M. L., Tsaoussoglou, M., Stiffler, D., Stefanakis, Z., Bixler, E. O., Chrousos, G. P. (2013). Effects of recovery sleep after one work week of mild sleep restriction on interleukin-6 and cortisol secretion and daytime sleepiness and performance. American Journal of Physiology-Endocrinology and Me- 


\section{tabolism, Vol. 305, No. 7, 890-896.}

Rutenfranz, J. and Knauth, P. (1976). Hours of work and shiftwork. Ergonomics, Vol. 19, 331-340.

Rutenfranz, J., Colquhoun, W. P., Knauth, P., and Ghata, J. N. (1977). Biomedical and psychosocial aspects of shiftwork. Scandinavian Journal of Work, Environment \& Health, Vol. 3, No. 4, 165-182.

(Received March 16, 2021; accepted April 22, 2021) 